VILELA, N.J.; MAKISHIMA, N.; OLIVEIRA, V.R.; COSTA, N.D.; MADAIL, J.C.M; CAMARGO FILHO, W.; BOEING, G.; MELO, P.C.T. Desafios e oportunidades para o agronegócio de cebola no Brasil. Horticultura Brasileira, Brasília, v.23, n.4, p.1029-1033, out-dez 2005.

\title{
Desafios e oportunidades para o agronegócio da cebola no Brasil
}

\author{
Nirlene J. Vilela' ${ }^{1}$; Nozomu Makishima ${ }^{1}$; Valter R. Oliveira' ${ }^{1}$; Nivaldo D. Costa ${ }^{2}$;oão Carlos M. Madail ${ }^{3}$; \\ Waldemar P. Camargo Filho ${ }^{4}$; Guido Boeing ${ }^{5}$; Paulo César T. de Melo ${ }^{6}$ \\ ${ }^{1}$ Embrapa Hortaliças, C. Postal 218, 70359-970 Brasília-DF; ${ }^{2}$ Embrapa Semi Árido, C. Postal 23, 56300-970 Petrolina-PE; ${ }^{3}$ Embrapa \\ Clima Temperado, C. Postal 403, 96001-970 Pelotas-RS; ${ }^{4}$ Instituto de Economia Agrícola, Av. Miguel Stefano, 3.900, 04301-903 São \\ Paulo-SP; ${ }^{5}$ Instituto CEPA, C. Postal 1587, 88034-001 Florianópolis-SC; ${ }^{6}$ USP-ESALQ, Depto. de Produção Vegetal, C.Postal 9, 13418- \\ 900 Piracicaba-SP; E-mails:nirlene@cnph.embrapa.br; nozomu@cnph.embrapa.br; ndcosta@cpatsa.embrapa.br; \\ valter@cnph.embrapa.br; madail@cpact.embrapa.br; camargofilho@iea-sp.gov.br; guido@cepa.com.br; pctmelo@esalq.usp.br
}

\section{RESUMO}

Este trabalho teve por objetivo descrever alguns aspectos socioeconômicos relacionados à cebola no Brasil e detectar os principais desafios e oportunidades que o produto apresenta para o agronegócio. A cultura, de caráter tipicamente "familiar" (88\%), gera cerca de 250 mil empregos somente no setor de produção. O consumo é estável em 85 mil t por mês. A consolidação do Mercosul e a conseqüente importação de cebola da Argentina somada à produção nacional tem causado excesso de oferta em alguns meses, gerando perdas e conseqüentes prejuízos para os produtores. O setor produtivo brasileiro necessita elevar o nível tecnológico para alcançar maior eficiência técnica e econômica. No entanto, é necessário que as regiões produtoras do Brasil e da Argentina tenham estabilidade de produção e que a quantidade ofertada seja suficiente para atender às necessidades de abastecimento em determinados períodos do ano, sem causar desequilíbio no mercado.

Palavras-chave: Alium cepa, agronegócio, competitividade, mercado, produção, importação.

\section{ABSTRACT}

\section{The challenges and the oportunities for the onion agribusiness}

The main objective of this work was to describe some socieconomic aspects of the onion production in Brazil and to detect the principal challenges and opportunities for the onion agribusiness. The onion cultivation in Brazil is a family activity (88\%), generating about 250 thousand jobs directly involved in the production. The onion consumption in Brazil is nearly 85 thousand $t$ per month. With the consolidation of the MERCOSUL, the onion import from Argentina and the national production has caused excess of supply in some months, generating losses and consequent damages for the producers. The Brazilian productive sector needs to improve the technological level of the onion production to reach greater technical and economic efficiency. However, it is necessary that Brazilian and Argentinian producers look for a better production forecast to avoid excess of supply during some periods of the year.

Keywords: Allium cepa, agribusiness, competitiveness, commercialization, production, importation.

\section{(Recebido para publicação em 4 de novembro de 2004 e aceito em 14 de setembro de 2005)}

$\mathrm{N}^{\mathrm{s}}$ o Brasil, como geradora de empregos e renda na agricultura, a cultura da cebola é uma atividade de elevada importância socioeconômica. Em razão de não existir uma política comercial restritiva entre os países do MERCOSUL, as entradas livres e intempestivas do produto estrangeiro, em detrimento das atividades produtivas do Brasil transferem-se para uma preocupação social mais ampla. Neste aspecto, a realização de estudos de natureza exploratória sobre a situação do mercado da cebola no Brasil nos últimos anos pode ser útil e necessária para subsidiar políticas setoriais e novas estratégias de produção e comercialização. As informações obtidas poderão auxiliar os agentes do agronegócio, instituições de pesquisa e desenvolvimento e formuladores de política setorial nas tomadas de decisão para redirecionar a cebolicultura brasileira, com vistas a elevar as condições de competitividade do produto.
O objetivo deste trabalho foi elaborar uma análise descritiva da situação de mercado da cebola no Brasil nos últimos três anos e, especificamente, detectar desafios e oportunidades para o agronegócio da cebola no Brasil.

\section{MATERIAL E MÉTODOS}

O trabalho foi elaborado com base na sistematização e análises das informações obtidas em reuniões técnicas para identificação de sistemas de produção predominantes nas principais regiões produtoras do País, realizadas com a participação dos agentes do agronegócio de cebola em SC, SP e PEBA, (VILELA et al., 2002). Adicionalmente, utilizaram-se os relatórios dos encontros intitulados "Seminário Nacional de Cebola - Seminário de Cebola do MERCOSUL", promovidos pelo agronegócio de cebola do Brasil e do MERCOSUL para escalonamento de oferta dos anos de 1999-2003 e as informações obtidas de fontes oficiais (IBGE e MDIC) e de outros trabalhos publicados. Os resultados foram descritos com base na sistematização e análise das informações, acerca da situação estrutural da produção e do comportamento de mercado (KING, 1967; KERBY, 1992).

\section{RESULTADOS E DISCUSSÃO}

No âmbito da agricultura brasileira, a cebola destaca-se como uma cultura de elevada importância socioeconômica. No aspecto de geração de emprego e renda, estima-se que a cadeia produtiva gere mais de 250 mil empregos diretos só no setor da produção (SAASP, 1997). De acordo com censo agropecuário de 1996 (IBGE, 2002), são mais de 102 mil produtores envolvidos na exploração econômica da cebola. A cultura de caráter tipicamente familiar $(88 \%)$ é res- 
N. J. Vilela et al.

Tabela 1. Calendário de colheita e comercialização de cebola no Brasil, 2003.

\begin{tabular}{|c|c|c|c|c|c|c|c|c|c|c|c|c|}
\hline \multirow{2}{*}{ Estados/indicações } & \multicolumn{12}{|c|}{ Meses } \\
\hline & 1 & 2 & 3 & 4 & 5 & 6 & 7 & 8 & 9 & 10 & 11 & 12 \\
\hline \multicolumn{13}{|l|}{ Santa Catarina } \\
\hline Colheita & $x$ & & & & & & & & & $x$ & $x$ & $\mathrm{x}$ \\
\hline Comercialização & $x$ & $x$ & $x$ & $x$ & $x$ & $x$ & & & & & $x$ & $x$ \\
\hline \multicolumn{13}{|l|}{ Rio Grande do Sul } \\
\hline Colheita & & & & & & & & & & $x$ & $x$ & $\mathrm{x}$ \\
\hline Comercialização & $x$ & $x$ & $\mathrm{x}$ & $x$ & & & & & & & $x$ & $x$ \\
\hline \multicolumn{13}{|l|}{ Paraná } \\
\hline Colheita & & & & & & & & & & $x$ & $x$ & $x$ \\
\hline Comercialização & $x$ & $x$ & $x$ & $x$ & $x$ & & & & & $x$ & $x$ & $x$ \\
\hline \multicolumn{13}{|l|}{ São Paulo } \\
\hline Colheita & & & & & $x$ & $x$ & & $x$ & $x$ & & $x$ & $x$ \\
\hline Comercialização & & & & & $x$ & $x$ & $x$ & $x$ & $x$ & $x$ & $x$ & $x$ \\
\hline \multicolumn{13}{|l|}{ Pernambuco e Bahia } \\
\hline Colheita & $x$ & $x$ & $x$ & $x$ & $x$ & $x$ & $x$ & $x$ & $x$ & $x$ & $x$ & $x$ \\
\hline Comercialização & $x$ & $x$ & $x$ & $x$ & $x$ & $x$ & $x$ & $x$ & $x$ & $x$ & $x$ & $x$ \\
\hline \multicolumn{13}{|l|}{ Minas Gerais } \\
\hline Colheita & & & & & $x$ & $x$ & $x$ & $x$ & $x$ & & & \\
\hline Comercialização & & & & & $x$ & $x$ & $x$ & $x$ & $x$ & $x$ & & \\
\hline
\end{tabular}

Fonte: ANACE,2003

ponsável pela sobrevivência no campo de um grande número de pequenos produtores que têm a cebola como única fonte de renda (VILELA et al., 2002). Uma das características marcantes do setor produtivo é que, mesmo nas médias e grandes propriedades, o sistema de produção é em parceria, ou seja, o empresário fornece a terra, capital, máquinas e insumos, enquanto as famílias parceiras entram com mão-de-obra para o cultivo, tratos culturais e colheita. Maior parte $(65,8 \%)$ dos produtores de cebola está concentrada nos extratos de área menores que 20 ha e são responsáveis por $51,7 \%$ da produção nacional (IBGE, 2002).

\section{Direções da cadeia produtiva}

No âmbito da cadeia produtiva, foram observados dois cenários. No segmento da produção, a preocupação com a competição externa colocou o atendimento às exigências do mercado como o principal centro de atenção do agronegócio da cebola. Neste aspecto, os produtores procuram por produto com maior competitividade em qualidade, custos e preços, optando por cultivares que garantam maior produtividade, apresentem maior grau de resistência às doenças e forneçam produtos comerciais com alto padrão de qualidade e maior produtividade. Estas preferências incluem cultivares de polinização aberta ou híbridas que proporcionem uma colheita uniforme, exatamente dentro da época programada. Adicionalmente, estas cultivares ou híbridos devem exibir padrão comercial similar ao do produto importado, especialmente quanto à uniformidade no tamanho do bulbo, cor, retenção de escamas e sabor. Ademais, percebe-se clara avidez por tecnologias para produção de cultivares de cebola menos pungentes (tipos doces ou suaves), mais adequadas para consumo fresco em saladas e tipos mais apropriados à industrialização (flocos e pó) e, também, cultivares adequadas para cultivo em sistemas orgânicos, como forma de agregar maior valor ao produto nacional (VILELA et al., 2002).

No segmento dos consumidores, observam-se preferências pela ótima qualidade do produto, diversificação de tipos varietais (tipos mais e tipos menos pungentes), produtos diferenciados (produção em sistemas orgânicos e agroecológicos), disposição dos produtos classificados e com melhor conservação pós-colheita. Nas observações de Boeing (2002), os consumidores preferem cebolas com bulbos globulares com casca de coloração avermelhada semelhante à cor do pinhão.
Diante destas exigências, as instituições de pesquisa públicas e privadas vêm ajustando suas atividades para atender às demandas dos produtores e dos consumidores, procurando desenvolver cultivares com as características que atendam às tendências atuais do mercado.

Distribuição das safras e preços de mercado

Em decorrência das exigências da cultura quanto ao fotoperíodo e temperatura, as cultivares regionais são diferenciadas. Na BA e PE, as cultivares predominantes são as importadas claras precoces e as da série IPA, com resistência à conservação de 30 a 45 dias após a colheita. Em SP, na safra do cedo, as cebolas produzidas são as claras precoces e, nas semeaduras tardias, as baias periformes. Em MG, GO e DF, predominam cultivares claras precoces e a baia periforme.

Em SC, as cultivares mais plantadas são as crioulas de casca escura, pungentes e com armazenamento pós-colheita, que pode se estender por até 6 meses, e as cultivares baias periformes precoces. No RS, os produtores cultivam tradicionalmente cebolas do grupo baia periforme, cuja semente é produzida no próprio estado. Desta forma, a oferta de cebola se distribui durante o ano todo (Tabela 1). 
Tabela 2. Programação da oferta de cebola em mil toneladas, 2003.

\begin{tabular}{lcccrrrrrrr}
\hline Mês & RS & SC & PR & SP & MG & BA/PE & GO & Brasil & ARG & MERCOSUL \\
\hline JAN & 16,50 & 39,60 & 18,00 & & 3,45 & 3,50 & & 81,05 & 4,00 & 85,05 \\
FEV & 15,00 & 55,00 & 19,20 & & 2,40 & 3,00 & & 94,60 & 9,00 & 103,60 \\
MAR & & 55,00 & 6,00 & & 3,30 & 4,50 & & 68,80 & 16,50 & 85,30 \\
ABR & & 39,60 & & & 1,47 & 19,09 & 2,00 & 62,60 & 28,50 & 90,66 \\
MAl & & 8,35 & & 9,25 & 2,18 & 25,32 & 6,00 & 51,10 & 34,50 & 85,60 \\
JUN & & & & 26,84 & 5,45 & 23,34 & 13,00 & 68,63 & 27,00 & 95,63 \\
JUL & & & & 26,23 & 9,22 & 20,15 & 11,40 & 66,90 & 19,50 & 86,40 \\
AGO & & & & 54,64 & 10,40 & 16,00 & & 81,04 & 7,50 & 88,54 \\
SET & & & & 45,79 & 10,25 & 14,10 & & 70,14 & 3,50 & 73,64 \\
OUT & & 0,45 & & 37,05 & 5,69 & 16,50 & & 59,70 & 59,69 \\
NOV & 1,00 & 4,40 & 6,40 & 30,52 & 4,44 & 14,00 & & 60,76 & 76,22 & \\
DEZ & 17,50 & 17,60 & 16,00 & 9,09 & 4,10 & 12,00 & & 76,76 & 76,22 \\
\hline Total & 50,00 & 220,00 & 65,60 & 239,24 & 62,36 & 171,50 & 32,40 & 841,09 & 150,000 & 991,09 \\
\hline
\end{tabular}

Fonte: ANACE, 2003.

Desde 1989, com o objetivo de organizar a produção e a comercialização da cebola no Brasil, os agentes do agronegócio do Brasil e da Argentina (Associações Regionais de Produtores, Associação Nacional de Produtores de Cebola-ANACE, comerciantes de cebola e de insumos para a cultura, pesquisadores, extensionistas) vêm realizando, anualmente, o Seminário Nacional da Cebola, quando registra-se um acordo para a consolidação de safras e a oferta anual dos dois países para o mercado brasileiro. Para 2003 foi programada a oferta de 841 mil t de cebola brasileira e de 150 mil t de cebola argentina (Tabela 2). Entretanto, de acordo com o IBGE (2004) a produção naquele ano foi de, aproximadamente, $1.187 \mathrm{mil} \mathrm{t}$, superando a oferta interna (841.099 t) em aproximadamente 346 mil t.

Os grandes Estados produtores como SC, SP e BA aumentaram a área plantada e a produção em relação ao ano anterior. Além disso, outros Estados de menor expressão econômica na cebolicultura, como é o caso de GO e MG vêm investindo na cultura e formando novos pólos ceboleiros. Por outro lado, é elevada a elasticidade-preço da oferta da cebola, característica econômica determinante no processo de produção e comercialização que expressa a sensibilidade da produção às variações de preços.

As variações de preços são estacionais e ocorrem com certa freqüência, o que pode ser resultado do efeito da "teoria da teia de aranha": em determinada época do ano, o preço é alto e a produção é baixa, e no ano seguinte, o produtor, estimulado pela alta do preço, aumenta a produção; o aumento da oferta tende a gerar queda dos preços. Isso pode ser observado no período de 1998 a 2003, o preço médio de cebola no mercado atacadista foi de $\mathrm{R} \$ 479,22$ por tonelada. A variação bianual dos preços mostrou pouca diferença entre os anos pares e ímpares. Os preços maiores ocorreram em anos com final par (de março a julho, ficaram acima da média), enquanto nos anos ímpares, a ocorrência de preços acima da média foi menor. A diferença da média entre anos pares e ímpares foi de $25 \%$.

O principal mercado atacadista no Brasil é a Ceagesp (Companhia de Entrepostos e Armazéns Gerais do Estado de SP), que comercializou em 2003, um volume de $92.379 \mathrm{t}$ de cebola nacional (76\%) e importada (24\%).

\section{Situação do consumo}

O consumo da cebola no Brasil apresentou tendência de aumento de produtos processados ao final da década de 1990 e início do século 21. Em razão do aumento da população urbana e da maior participação da mulher no mercado de trabalho, as famílias passaram a fazer maior número de refeições fora do domicílio. Apesar da redução do consumo domiciliar de bulbos de $6,5 \mathrm{~kg} /$ hab/ano em 1987 para 3,5 kg/hab/ano em 2003 (IBGE, 2004), vem aumentando o consumo de cebola processada com pasta de alho e sal, purês e catchup e cebolas desidratadas.

O consumo institucional (setor de refeições coletivas) evoluiu no período de 1998/2002 em 37\% (BRASIL, 2002) e, em levantamento recente realizado por Cabrera Filho (2004) relata que o consumo médio de cebola no Brasil situa-se em torno de 85 e 90 mil t/mês. É importante ressaltar que o IBGE pesquisa o consumo familiar no âmbito dos domicilios. Para formar uma ideia sobre a quantidade consumida em todos os segmentos do consumo, além das unidades familiares deve-se pesquisar o consumo das agroindústrias e o chamado consumo institucional (setores de refeições coletivas representados pelas lojas de comidas prontas, restaurantes, merenda escolar, hospitais e outros).

Importações brasileiras para o abastecimento nacional

As importações brasileiras aumentaram nos últimos anos. Uma das razões que pode explicar este crescimento é a boa aparência da cebola argentina, associada a sua boa conservação pós-colheita. Isto contribui para que os consumidores optem pelo produto importado, o que implica na transferência de valor agregado para o país vizinho (CAMARGO FILHO, 1999).

De acordo com Porter (1993) a principal vantagem competitiva entre as nações consiste em aumentar sucessivamente a produtividade dos fatores e diferenciar os produtos em excelência de qualidade. 
Tabela 3. Comportamento do mercado de cebolas frescas em 2003.

\begin{tabular}{lccccccc}
\hline & $\begin{array}{c}* \text { Oferta } \\
\text { A }\end{array}$ & $\begin{array}{c}\text { Importação } \\
\text { B }\end{array}$ & $\begin{array}{c}\text { Estoque } \\
\text { C = A + B }\end{array}$ & $\begin{array}{c}* * \text { Consumo } \\
\text { D }\end{array}$ & $\begin{array}{c}\text { Suficiência } \\
\text { estoques } \\
\text { E= D - C }\end{array}$ & $\begin{array}{c}\text { Exportação } \\
\text { F }\end{array}$ & $\begin{array}{c}\text { Suprimento do } \\
\text { mercado } \\
=\text { a }(\text { E - F) }\end{array}$ \\
\hline JAN & 81.050 & 3.925 & 84.975 & 85.000 & -25 & 30,7 & $-55,7$ \\
FEV & 94.600 & 9.285 & 103.885 & 85.000 & 18.885 & 0,6 & $18.828,7$ \\
MAR & 68.800 & 37.757 & 106.557 & 85.000 & 21.557 & 0 & $40.385,7$ \\
ABR & 62.160 & 45.922 & 108.082 & 85.000 & 23.082 & 0,3 & $63.467,4$ \\
MAI & 51.100 & 44.662 & 95.762 & 85.000 & 10.762 & 0,5 & $74.228,9$ \\
JUN & 68.632 & 12.879 & 81.511 & 85.000 & -3.489 & 0,3 & $70.739,6$ \\
JUL & 66.905 & 10.810 & 77.715 & 85.000 & -7.285 & 0 & $63.454,6$ \\
AGO & 81.038 & 5.345 & 86.383 & 85.000 & 1.383 & 194,5 & $64.643,1$ \\
SET & 70.145 & 1.335 & 71.480 & 85.000 & -13.520 & 422 & $50.701,1$ \\
OUT & 59.691 & 344 & 60.035 & 85.000 & -24.965 & 248,7 & $25.487,4$ \\
NOV & 60.760 & 111 & 60.871 & 85.000 & -24.129 & 1,1 & $1.357,3$ \\
DEZ & 76.218 & 302 & 76.520 & 85.000 & -8.480 & 1,7 & $-7.124,4$ \\
\hline TOTAL & 841.099 & 172.677 & 1.013 .776 & 1.020 .000 & -6.224 & 900,4 &
\end{tabular}

Fonte: BRASIL. Ministério do Desenvolvimento da Indústria e Comércio (2004a, 2004b); ANACE (2003)

*Programada; **estimado

Tabela 4. Sistemas predominantes e custos de produção de cebola no Brasil.

\begin{tabular}{llc}
\hline Principais produtores & Sistemas de produção predominantes & $\begin{array}{c}\text { Custos de } \\
\text { produção } \\
\text { (R\$) }\end{array}$ \\
\hline Santa Catarina & - Cultivo mínimo com microtrator (15.000 t/ha) & $3.981,12$ \\
& - Cultivo mínimo com trator (25.000 t/ha) & $6.475,36$ \\
& - Cultivo mínimo com trator (35.000 t/ha) & $8.194,94$ \\
São Paulo & - Sistema agroecológico (10 t/ha) & $3.256,00$ \\
Petrolina-PE Juazeiro-BA & Transplante (25 t/ha) & $7.754,38$ \\
Rio Grande do Sul & Transplante (20tha) & $4.519,96$ \\
\hline
\end{tabular}

Fonte: Vilela et al., 2002.

A cebola fresca ou refrigerada foi o principal tipo importado pelo Brasil (99\%). Nos últimos anos, as importações de alguns tipos, como cebola seca, foram reduzidas. Outras, tais como echalotes e conservas não estão constando da pauta de importações de cebolas.

A proposta da Argentina de lançar 150 mil $t$ de cebola fresca no mercado brasileiro em 2003 realizou-se com um acréscimo de 21,4 mil t. Em adição às excessivas importações da Argentina (171,4 mil t) o Brasil ainda importou mais de 1,2 mil t de outros países.

Em 2003, o Brasil importou cebola fresca desnecessária e intempestivamente durante o ano inteiro, não somente da Argentina como planejado, mas também de outros países. A excessiva quantidade importada, somada aos estoques de SC, RS e PR, que são comercializados na mesma época de maior entrada do produto estrangeiro, ultrapassam as reais necessidades de abastecimento do mercado, resultando em perdas para a cebolicultura brasileira. A ocorrência deste fato pode ser explicada pela falta de um planejamento sistemático da produção: planta-se demais e perde-se muito, seja por deficiência de armazenagem, seja pelo comportamento de mercado no processo de expurgo da carga excedente. Subtraindo da produção interna de 1.187 mil t (IBGE,2004) as necessidades de consumo de 1.020 mil t conforme tabela $3 \mathrm{e}$ as exportações de 900,4 t, o resultado é

Este resultado evidencia que a importação de cebola fresca é desncessária, uma vez que a safra brasileira foi mais do que suficiente para suprir o mercado nacional. Entretanto, por força de acorum excedente de produção equivalente a $166,2 \mathrm{t}$. do com o MERCOSUL, foi planejado um espaço de 150 mil t no mercado brasileiro para a produção argentina, porém a Argentina destinou ao Brasil 171.436 $\mathrm{t}$ que, somadas às importações de outros países, totalizaram $172.677 \mathrm{t}$ importadas. Considerando a oferta programada do Brasil (841.099 t) mais as importações realizadas $(172.677 \mathrm{t}$ ) menos as exportações (900,4 t), observa-se um déficit operacional no mercado (-7.124 t). Quando se correlaciona o excedente da produção à oferta programada, consumo e exportações, verifica-se que as importações representaram uma parcela de $51 \%$ no total excedente.

No Brasil ocorrem situações em que a cebola, como única fonte de renda dos produtores, precisa ser comercializada imediatamente após a colheita, até mesmo sem cura, para recuperar o escasso capital de giro e sustentar a sobrevivência da família. Sem cura, a cebola, além da aparência não-atrativa, fica mais exposta às deteriorações. Além dos bulbos mal curados, verifica-se ainda o apodrecimento por falta de ambiente adequado ao armazenamento, bulbos atacados por pragas e doenças, manuseio e transporte feito sem cuidados, má aparência visual dos bulbos (desuniformes, descascados ou com cascas muito finas). Em algumas regiões, como NE e SE são utilizadas cultivares inadequadas que não apresentam resistência ao armazenamento. Pelo fato des- 
tas cultivares de cebola possuírem baixo teor de sólidos solúveis totais na sua composição, imediatamente após serem colhidas e curadas, necessitam ser comercializadas, gerando um grande fluxo de cebola de baixa qualidade no comércio. Esta situação traz, consequentemente, quedas de preços, reduzindo a rentabilidade da cultura e elevando os níveis de perdas. Assim, no segundo semestre, observam-se quedas de preço por excesso de oferta, em razão da impossibilidade de armazenamento. No primeiro semestre, o escoamento dos estoques armazenados da cebola de ciclo tardio confrontase com os da cebola importada.

No Brasil, a característica marcante da oferta de cebola é a estacionalidade da produção. Levando-se em conta o nível da tecnologia adotado pelos produtores e as condições de clima, muitas vezes desfavoráveis à cultura, as médias de produtividade são baixas, variando de 15 a 17 t/ha. De acordo com Vilela et al. (2002), os custos médios operacionais da cebola variam de acordo com o nível tecnológico da cultura (Tabela 4).

De acordo com Tosi (2003), na Argentina, o custo médio operacional total da cebola, em 2003, foi de U\$ 1.465,02, ou seja, $\mathrm{R} \$ 2.809,59$, para o nível de produtividade de 1200 bolsas de $25 \mathrm{~kg}$. A produtividade média da cebola Argentina, confirmada por Galmarini (2004) varia entre de 26 a 28 t/ha, levando-se em conta as cultivares de dia curto, intemediário e longo. Para o caso das cultivares de dia longo tipo Valencianas, que ocupam $80 \%$ da área plantada a produtividade média situa-se em torno de 33 t/ha. Diante das condições produtivas do Brasil, é factível esperar um cenário favorável para a Argentina (BARBERO; CASTELLANO; LUCARENA, 2000). $\mathrm{Na}$ Argentina existe maior integração dos setores produtivos com o governo. Além disso, o solo fértil necessita de pouca adubação, principalmente de fósforo e potássio, o que contribui para a redução dos custos operacionais. Na produção de cebola, outro fator que explica as vantagens da Argentina em relação ao Brasil é o clima que favorece os ganhos de produtividade e a qualidade dos bulbos (CAMARGO FILHO, 2000).

As situações de produção e comercialização permitem a conclusão de que a permanência da cebola do Bra- sil ou da Argentina no mercado brasileiro passa pela questão da competitividade. Apesar da produtividade média da cebola brasileira ser mais baixa,quando comparada à da Argentina e os custos de produção mais elevados, novas fronteiras de produção estão surgindo em São Gotardo (MG), Cristalina (GO) e Chapada Diamantina (BA). Nesses novos polos predominam lavouras de grande extensão, mecanizadas, operando com elevado nível tecnológico. A produtividade média desses locais tem sido superior a 50 t/ha e qualidade comparável à do similar importado.

Na região de Irecê (BA), a cultura da cebola vem evoluindo de forma considerável nos últimos anos. Os produtores de Irecê vêm adotando tecnologia de produção superior à da tradicional zona do submédio São Francisco (PEBA). Consequientemente, as médias de produtividade obtidas têm sido superiores a $25 \mathrm{t} / \mathrm{ha}$. Estas novas fronteiras de produção têm contribuído, de forma significativa, para as mudanças no cenário da comercialização de cebola do país e, diretamente, são também responsáveis pela fragilidade dos pequenos produtores tecnologicamente menos eficientes.

Na situação de desarticulação apresentada pelo mercado da cebola fresca, em razão de excesso de produção e excesso de importações, torna-se necessária a racionalização da produção (redução de área média plantada nas regiões e elevação do nível tecnológico dos sistemas) para que sejam gerados ganhos de produtividade com capacidade de diluir custos e, ao mesmo tempo, elevar a qualidade da cebola nacional.

A vantagem competitiva do produto da Argentina no mercado brasileiro deve se manter enquanto o país vizinho cuidar da qualidade e da apresentação da cebola que exporta, a menos que o Brasil, e em particular os estados do Sul, invistam mais em tecnologias, com vistas a alcançar maior eficiência técnica e econômica dos atuais sistemas produtivos. Outra alternativa é diversificar a oferta de variedades, procurando diferenciar o produto em relação ao concorrente, como a produção de cebola tipo doce ou em sistemas orgânicos ou agroecológicos. Nos estados do NE, onde o clima apresenta condições favoráveis, a produção de cebola tipo salada (cebola doce) com vistas às exportações para os Estados Unidos e Europa, pode tornar-se uma alternativa rentável para os produtores.

\section{LITERATURA CITADA}

ANACE. Escalonamento mensal da oferta de cebola para 2003: em toneladas. In: SEMINÁRIO NACIONAL DE CEBOLA, 15; SEMINÁRIO DE CEBOLA DO MERCOSUL, 16, 2003, Petrolina. Anais... Petrolina: Embrapa Semi-Árido, 2003. BARBERO, A.; CASTELLANO, A.; LUCANERA, G. Situação actual y perpectivas del cultivo de cebolla en el Valle Bonaerense del Rio Colorado. In: REUNIÓN ANUAL DE LA AAEA, 29., 1998, La Plata. Trabajos y comunicaciones.. Buenos Aires: AEEA, 2000.

BOEING, G. Fatores que afetam a qualidade da cebola na agricultura familiar catarinense. Florianópolis: Instituto Cepa, 2002. 88 p.

BRASIL. Ministério do Desenvolvimento da Indústria e Comércio. Importação brasileira, 07031019: outras cebolas frescas ou refrigeradas. Disponível em: $\langle$ http://aliceweb.desenvolvimento.gov.br >. Acesso em: 22 jan. 2004a.

BRASIL. Ministério do Desenvolvimento da Indústria e Comércio. Exportação brasileira, 07031019: outras cebolas frescas ou refrigeradas. Disponível em: <http://aliceweb.desenvolvimento.gov.br>. Acesso em: 22 jan. 2004b.

BRASIL. Ministério da Integração Nacional. Refeições coletivas: um segmento que apresenta oportunidades para o produtor. Frutifatos, Brasília, DF. Edição 3. p.2-10, 2002.

CABRERA FILHO, J. Relatório da produção de cebola no Brasil: 2004. São Paulo: Secretaria da Agricultura e Abastecimento. 2004. 5 p. (Documento).

CAMARGO FILHO, W.P. Produção e mercado de cebola no MERCOSUL: 1990-98. Informações Econômicas, São Paulo, v.29, n.4, p.19-30, 1999. CAMARGO FILHO, W.P. Alterações no mercado de cebola com o MERCOSUL: Informações Econômicas, São Paulo, v.32, n.14, p.41-49, 2000. GALMARINI, C. Rendimiento da cebolla en Argentina. INTA. Crgalmarini@mendoza.inta.gov.ar (comunicação via E-mail em 03/11/2004).

IBGE. Censo Agropecuário:1996.Número de informantes por extratos de áreas. Disponível em: <http:/ /www.sidra.ibge.gov.br>. Acesso em: 20 dez. 2002. IBGE. Produção agrícola municipal de cebola. Disponível em: <http://www.ibge.gov.br〉. Acesso em: 09 fev. 2004.

IBGE. Pesquisa de orçamento familiar-2003. Disponível em: <http://www.ibge.gov.br>. Acesso em: 18 abr. 2004

KERBY, J.K. Essencial of marketing management. Chicago: South-Western Publishung Company, 1992. 696 p.

KING, R.W. Análise quantitativa em administração mercadológica. São Paulo: USP, 1967682 p.

PORTER, M.E. A vantagem competitiva s das Nações. Rio de Janeiro: campus,1993. 897 p.

SAASP. Repensando a agricultura paulista. São Paulo, 1997. 43 p.

TOSI, J.C. INTA Balcarce: suplemento económico n. 25: costo operativo de cebolla. Disponível em: $<\mathrm{http}$ / /www.inta.gov.ar/balcarce/info/documentos/econo/ suple/25/cebolla.htm> Acesso em: 09 dez. 2003.

VILELA, N.J.; MAKISHIMA, N.; VIEIRA, R.C.M.T.; CAMARGO FILHO, W.P.; MADAIL, J.C.M.; COSTA, N.D.; BOEING G.; VIVALDI, L.F.; WERNER, H. Identificação de sistemas de produção de cebola nos principais Estados produtores: relatório final de pesquisa - subprojeto 13.2001.86507. Brasília: Embrapa Hortaliças, 2002. 